\section{HLA-B27 Polymorphism in Han Chinese Patients with Ankylosing Spondylitis: A Distinctive Disease Association for $B * 2715$ in a Multiplex Family}

\section{To the Editor:}

Ankylosing spondylitis (AS) is an inflammatory disorder mainly affecting the axial joints, and distinguished by a significant association with HLA-B27. The HLA-B27 gene has a remarkable polymorphism. According to data published in the international ImMunoGeneTics database (IMGT, release 2.24.0), 53 alleles exist, encoding 44 different proteins.

The aim of our study was to investigate the distribution of HLA subtype B27 in Han Chinese patients with AS. A registration and followup data bank were established for patients with spondyloarthritis ( $\mathrm{SpA}$ ) who presented at our hospital. The cohort consisted of 408 patients with AS, registered from October 2004 to December 2006. Based on the assignment of random numbers, 100 AS samples were drawn randomly from the data bank. Of these, 2 samples from the same family were treated as duplicates and were excluded. Then, the study consisted of 98 independent individuals, all Han Chinese.

Luminex liquid array combined with polymerase chain reaction (PCR)-SSOP (AccuPlex ${ }^{\mathrm{TM}}$, Dynal-Invitrogen, USA) was used to obtain low-resolution HLA-B genotype typing. High-resolution HLA-B27 typing of B27-positive individuals was carried out by PCR-SSP (PEL-FREEZ, Dynal-Invitrogen). Sequence-based typing (SeCore ${ }^{\mathrm{TM}}$ Sequencing Kits, Dynal-Invitrogen) was done when necessary. Of 98 subjects, 93 were B27-positive (94.9\%). Three different B27 alleles, B*2704(76/93, $81.72 \%), \mathrm{B} * 2705(12 / 93,12.9 \%)$, and $\mathrm{B} * 2715(5 / 93,5.38 \%)$, were identified. As $B * 2715$ was a rare allele, sequence-based typing was used to retest $\mathrm{B} * 2715$-positive samples to confirm the result. A comparison of the frequency of B*2704 and B*2705 in Han Chinese patients with AS and AS patients in other areas of the world showed a significant difference between Han Chinese and Caucasians, as well as among Asian Mongoloid subpopulations (Table 1).

Five subjects in our study were found to carry the very rare HLA-B27 allele $B * 2715$. All 5 patients were men, with an average age of 28.8 years. The mean course of the disease was 11 years, and the mean age of symp- tom onset was 17.8 years. Two patients had developed AS at an early age, 5 and 9 years old.

Since, to date, the presence of $B * 2715$ has not been reported in healthy Chinese, we carried out a family survey for the allele in a $\mathrm{B} * 2715$ positive familial case. Of the 20 members of that family, 7 patients with AS were identified, 6 of whom were still alive. Blood samples obtained from these 6 family members showed that each one carried $B * 2715$. Thus, the $B * 2715$ status was cosegregated with AS in this pedigree. The only exception was a healthy, B*2715-positive 9-year-old boy, in whom it may be too early to determine whether AS will eventually develop. No other B27 subtype was detected in this family (Figure 1).

The focus of this study was B27 polymorphism in the Han Chinese AS population. Results show that $\mathrm{B} * 2704$ is the predominant subtype in AS patients of the Han Chinese population, followed by $B * 2705$. Five $B * 2715$-positive subjects were found in our study population. HLA-B*2715, which is an extremely rare B27 allele, was first discovered and submitted to the IMGT database in 1998. B*2715 in healthy Chinese has not been reported. In a search of the PubMed and EMBASE databases from 1998 onwards, only 2 articles describing 4 individuals who carried the $\mathrm{B} * 2715$ subtype were found. Garcia-Fernandez, et $a l^{8}$ investigated the B27 polymorphism in 6 Asian populations; they found 2 patients with AS among 66 subjects (47 AS patients and 19 controls) in Thailand. Voorter, et $a l^{9}$ described $2 \mathrm{~B} * 2715$-positive individuals, but did not mention whether they had SpA. In a study by Han, et al ${ }^{10}$, of 100 Chinese patients with AS, 6 were $B * 2715$-positive. Thus, to date, based on literature reports, B*2715 is detected almost only in patients with AS. Here, we confirmed this association in a Han Chinese AS pedigree.

The genetic sequences of $\mathrm{B} * 2704$ and $\mathrm{B} * 2715$ differ in positions 559 and 560, resulting in an amino acid change from glutamic acid to threonine at position 163, where glutamic acid is present in all B27 subtypes except $\mathrm{B} * 2715$. The $\mathrm{B} * 2715$ allele might have arisen by a gene conversion event from $B * 2704$. If this base change were a neutral variation, then $B * 2715$ should be expected to occur in healthy people; however, this subtype, albeit rare, was almost exclusively detected in patients with AS. Thus, B*2715 seems to have a special association with AS. Whether the differences between $B * 2704$ and $B * 2715$ enhance the association between the latter and AS is currently not known.

Table 1. Comparison of the $\mathrm{B} * 2704$ and $\mathrm{B} * 2705$ constituent ratio between Han Chinese patients with ankylosing spondylitis (AS) and those in other areas of the world. The constituent ratios of B*2704 and B*2705 in our study population were 76/93 and 12/93, respectively. Significant differences for the distribution of B27 subtypes between patients with AS from different ethnic groups are indicated.

\begin{tabular}{|c|c|c|c|c|c|}
\hline Report & Nation & Allele & $\begin{array}{l}\text { Constituent } \\
\text { Ratio }\end{array}$ & $\begin{array}{r}\text { Comparison with } \\
\text { Chi-square }\end{array}$ & $\begin{array}{l}\text { Idy Population } \\
\mathrm{p}\end{array}$ \\
\hline \multirow[t]{2}{*}{ Chen ${ }^{1}$} & \multirow[t]{2}{*}{ Taiwan } & $B * 2704$ & $97.83(180 / 184)$ & 22.87 & $<0.001$ \\
\hline & & $\mathrm{B} * 2705$ & $1.63(3 / 184)$ & 15.33 & $<0.001$ \\
\hline \multirow[t]{2}{*}{ Lopez-Larrea $^{2}$} & \multirow[t]{2}{*}{ Thailand } & B*2704 & $91.11(41 / 45)$ & 2.07 & 0.15 \\
\hline & & $\mathrm{B} * 2705$ & 0 & 4.838 & 0.028 \\
\hline \multirow[t]{2}{*}{ Lopez-Larrea $^{2}$} & \multirow[t]{2}{*}{ India } & B*2704 & $40(18 / 45)$ & 24.30 & $<0.001$ \\
\hline & & $\mathrm{B} * 2705$ & 0 & 4.838 & 0.028 \\
\hline \multirow[t]{2}{*}{ Yamaguchi $^{3}$} & \multirow[t]{2}{*}{ Japan } & $\mathrm{B} * 2704$ & $66.67(14 / 21)$ & 2.34 & 0.126 \\
\hline & & $\mathrm{B} * 2705$ & $33.33(7 / 21)$ & 5.15 & 0.023 \\
\hline \multirow[t]{2}{*}{ Oguz $^{4}$} & \multirow[t]{2}{*}{ Turkey } & B*2704 & $1.96(1 / 51)$ & 84.22 & $<0.001$ \\
\hline & & $B * 2705$ & $66.67(34 / 51)$ & 43.79 & $<0.001$ \\
\hline \multirow[t]{2}{*}{$\operatorname{Armas}^{5}$} & \multirow[t]{2}{*}{ Azores } & B*2704 & 0 & 66.71 & $<0.001$ \\
\hline & & $\mathrm{B} * 2705$ & $93.75(30 / 32)$ & 69.75 & $<0.001$ \\
\hline \multirow[t]{2}{*}{ Paladini ${ }^{6}$} & \multirow[t]{2}{*}{ Sardinia } & $\mathrm{B} * 2704$ & 0 & 71.61 & $<0.001$ \\
\hline & & $\mathrm{B} * 2705$ & $83.33(30 / 36)$ & 58.63 & $<0.001$ \\
\hline \multirow[t]{2}{*}{ Paladini ${ }^{6}$} & \multirow[t]{2}{*}{ Italy } & B*2704 & 0 & 93.41 & $<0.001$ \\
\hline & & $\mathrm{B} * 2705$ & $73.21(41 / 56)$ & 55.48 & $<0.001$ \\
\hline \multirow[t]{2}{*}{ Cipriani $^{7}$} & \multirow[t]{2}{*}{ Venezuela } & $B * 2704$ & 0 & 85.09 & $<0.001$ \\
\hline & & B*2705 & $68.75(33 / 48)$ & 45.44 & $<0.001$ \\
\hline
\end{tabular}




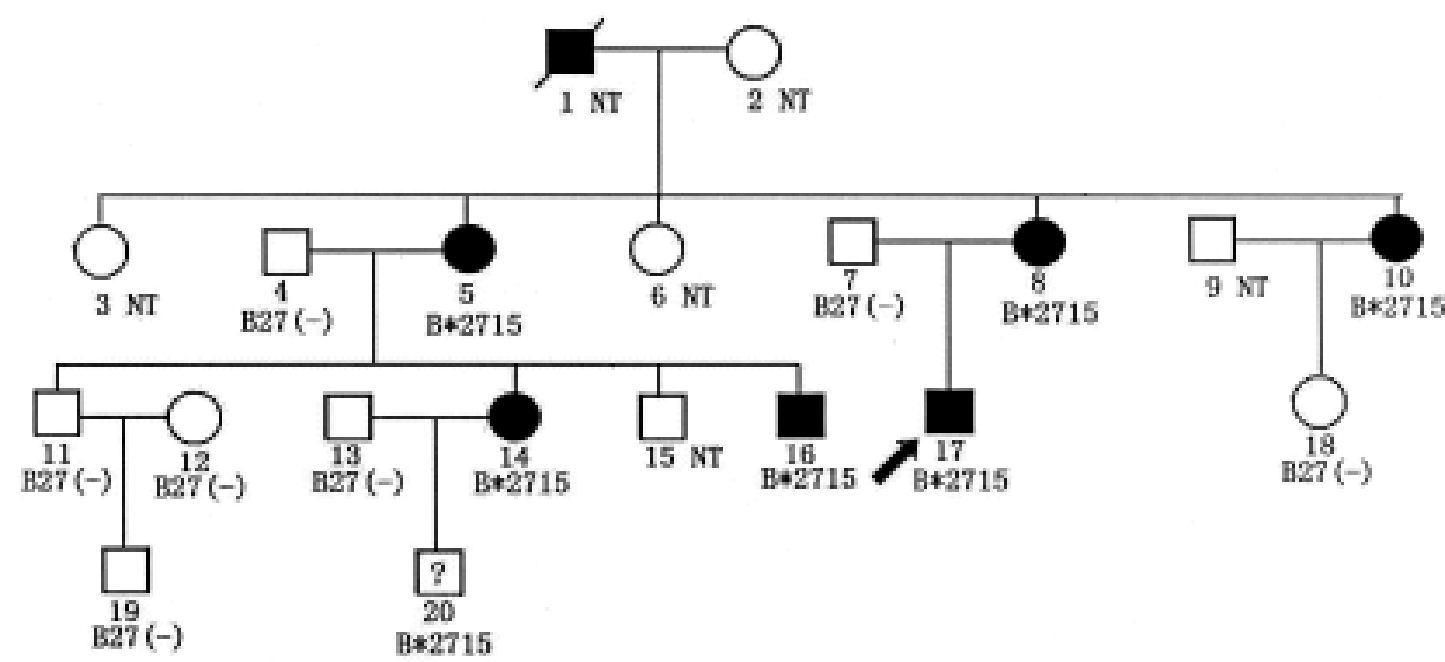

Figure 1. Family tree and segregation of $\mathrm{B} * 2715$ and ankylosing spondylitis (AS) determined in our study. Family members are numbered, and the affected members shaded. 1, 5, 8, 10, 14, 16, and 17 are patients with AS. Except patient 1 (not tested), all were B*2715. Patient 20 was healthy and B*2715-positive, but only 9 yrs old and it remains to be seen whether he will eventually develop AS. Family members 1, 2, 3, 6, 9, and 15 were unavailable for blood testing. NT: not tested.

ZHEN WU, MD, PhD; YIKUN MOU, MD, PhD; ZHIMING LIN, MD, PhD; JINXIAN HUANG, MD; QIUJING WEI, BS; JIERUO GU, MD. Address correspondence to Professor J. Gu, Director of Division of Rheumatology, Department of Medicine, The Third Affiliated Hospital of Sun Yat-sen University, Tianhe Road 600, Guangzhou 510630, People's Republic of China. E-mail:gujieruo@163.com

Supported by Distinguished Young Scientist Research Grant (30325019) and National Natural Science Foundation of China grant (30571735). Drs. Wu and Mou contributed equally.

\section{REFERENCES}

1. Chen IH, Yang KL, Lee A, Huang HH, Lin PY, Lee TD. Low frequency of HLA-B*2706 in Taiwanese patients with ankylosing spondylitis. Eur J Immunogenet 2002;29:435-8.

2. Lopez-Larrea C, Sujirachato K, Mehra NK, Chiewsilp P, Isarangkura D, Kanga U, et al. HLA-B27 subtypes in Asian patients with ankylosing spondylitis. Evidence for new associations. Tissue Antigens 1995;45:169-76.

3. Yamaguchi A, Ogawa A, Tsuchiya N, Shiota M, Mitsui H, Tokunaga K, et al. HLA-B27 subtypes in Japanese with seronegative spondyloarthropathies and healthy controls. J Rheumatol 1996;23:1189-93.

4. Oguz FS, Ocal L, Diler AS, Ozkul H, Asicioglu F, Kasapoglu E, et al. HLA B-27 subtypes in Turkish patients with spondyloarthropathy and healthy controls. Dis Markers 2004;20:309-12.
5. Armas JB, Gonzalez S, Martinez-Borra J, Laranjeira F, Ribeiro E, Correia J, et al. Susceptibility to ankylosing spondylitis is independent of the Bw4 and Bw6 epitopes of HLA-B27 alleles. Tissue Antigens 1999;53:237-43.

6. Paladini F, Taccari E, Fiorillo MT, Cauli A, Passiu G, Mathieu A, et al. Distribution of HLA-B27 subtypes in Sardinia and continental Italy and their association with spondylarthropathies. Arthritis Rheum 2005;52:3319-21.

7. Cipriani A, Rivera S, Hassanhi M, Marquez G, Hernandez R, Villalobos C, et al. HLA-B27 subtypes determination in patients with ankylosing spondylitis from Zulia, Venezuela. Hum Immunol 2003;64:745-9.

8. Garcia-Fernandez S, Gonzalez S, Mina Blanco A, Martinez-Borra J, Blanco-Gelaz M, Lopez-Vazquez A, et al. New insights regarding HLA-B27 diversity in the Asian population. Tissue Antigens 2001;58:259-62.

9. Voorter CE, Swelsen WT, van den Berg-Loonen EM. B*27 in molecular diagnostics: impact of new alleles and polymorphism outside exons 2 and 3. Tissue Antigens 2002;60:25-35.

10. Han JY, Xiong P, Yan P, Shao SY, Xiong P, Wu XW, et al. Detection of HLA-B27 subtypes in ankylosing spondylitis patients by PCR-SSP [in Chinese]. Di 3 Jun Yi Da Xue Xue Bao 2003;25:1394-5.

J Rheumatol 2009;36:12; doi.10.3899/jrheum.090341 